\title{
Mechanical behaviour and permeability of geopolymer mortars
}

\author{
Mateusz Sitarz ${ }^{1}$, Marta Choińska ${ }^{2, *}$, Izabela Hager $^{1}$, and Abdelhafid Khelidj $^{2}$ \\ ${ }^{1}$ Cracow University of Technology, Faculty of Civil Engineering, Chair of Building Materials, \\ Warszawska 24, 31-155 Cracow, Poland \\ ${ }^{2}$ Nantes University - IUT Saint-Nazaire, Research Institute in Civil and Mechanical Engineering \\ GeM - UMR CNRS 6183, 58, rue Michel Ange, 44600 Saint Nazaire, France
}

\begin{abstract}
Geopolymers may be considered as an alternative materials to Portland cement ones, providing an opportunity to exploit industrial wastes or co-products with promising short and long-term performances in the construction field, f.ex. for reparation issues. However, these materials are porous and consequently their durability depends on the risk of intrusion of aggressive agents. In order to assess their durability, we propose to investigate in this study gas permeability of sound and mechanically loaded specimens. Loading is performed using a splitting tensile test driven by a crack opening displacement up to a level of 50 microns. Tests are performed on four types of blended fly-ash (FA) and ground granulated blast furnace slag (GGBFS) geopolymer mortars, containing four different levels of GGGBF slag in the binder: $0 \%, 10 \%, 30 \%$ and $50 \%$ wt. Results show a positive effect of blending with slag in terms of modulus of elasticity and tensile and compressive strength, as well as the permeability. However, permeability recovery after cracking is the lowest when blending is the highest.
\end{abstract}

\section{Introduction}

Geopolymers and alkali activated aluminosilicates are considered a sustainable alternative to Portland cement providing an opportunity to reduce carbo dioxide emissions in the construction sector [1]. Their production requires metakaolinite or industrial waste materials containing aluminosilicates, such as fly ash (FA) and granulated ground blast furnace (GGBFS) [2]. Aluminosilicates for geopolymer manufacturing can readily be found either as raw minerals or in widely available waste streams. Under highly alkaline conditions, those raw materials have binding properties that allow the synthesis of strong and durable composites [3, 4]. Numerous pieces of research have been carried out to provide more insight into the method of synthesis and the best composition of geopolymers [5, 6]. Nevertheless, there is still a great need to provide more data that will allow the development of methods for designing geopolymers. The geopolymerisation process is strongly dependent on the source, composition and particle size of the aluminosilicates; thus a database on the chemistry, reactivity and dissolution mechanisms of various precursors must be completed

*Corresponding author: Marta.Choinska@univ-nantes.fr 
[5]. There are many examples of geopolymer mixes and alkali-activated materials (AAM) in the literature. The properties of those binders depend on the chemical composition of the source material. Aluminosilicate systems based on FA with low calcium content required a heat treatment curing cycle that makes this material well suited for prefabrication and precast manufacturing processes $[7,8,9,10]$ but they jeopardize their sustainable character because they require a significant amount of thermal energy to set and harden.

The research results presented in the literature show high chemical durability $[11,12]$, fire-resistance [13] and mechanical parameters similar or higher when compared to cementitious materials [14]. Geopolymers have a porous structure [14], consequently their durability depends on the possibility of the intrusion of aggressive agents. The research results on geopolymer porosity show that their pore size distribution has a form of a bell curve with the center in a mesoporous region $[15,16]$. There are some differences in pore size distribution between materials with sodium or potassium alkaline solution. According to the literature [17], the peak for sodium geopolymers is situated above $30 \mathrm{~nm}$. For the potassium geopolymer, the peak is usually situated in the lower range between 7 and $30 \mathrm{~nm}$.

The investigation of nitrogen absorption porosimetry $[10,18]$ shows that the potassiumbased geopolymers exhibited also about 3 times higher specific area than sodium-based geopolymers. Several publications on transport properties in geopolymers are currently available. According to the literature [19], the diffusion coefficient of geopolymer composites changes values in a wide range. For geopolymers mortars with a sodium alkaline solution, this value is usually around $10-11 \mathrm{~m}^{2} / \mathrm{s}$. Research results on transport properties show that metakaolin-based geopolymer indicate lower permeability at early age compared to the cement paste with similar open porosity. Permeability is a parameter that indirectly influences the durability of a porous material by governing the penetration rate of aggressive agents responsible for degradation under a pressure gradient, or directly in the case of structures with tightness role. Hence, as scientific data in this field are quite limited, there is a clear motivation to investigate the permeability of geopolymer mortars and its evolution due to mechanical loading and cracking.

One of the most beneficial solutions to improve geopolymer properties is the use of blended binder, often FA with GGBFS [20]. The replacement a part of fly ash by GGBFS reduces the workability and setting time of geopolymer mortars. At the same time, a larger amount of GGBFS in the binder should improve mechanical and transport properties of geopolymer materials.

In view of lowering the energy demand of the geopolymer production process, blends of FA from power plant with GGBFS were used in this research. This procedure allowed setting to be obtained at room temperature with no need for curing at an elevated temperature. FA was blended with GGBFS at three levels of addition: 10, 30, $50 \mathrm{wt} . \%$ and compared to 100 wt.\% FA based geopolymer mortar. The increase of GGBFS content in fly ash-based geopolymer affected splitting, flexural and compressive strengths and impacted gas permeability and its evolution with mechanical loading.

\section{Materials and methods}

\subsection{Materials}

The study used siliceous fly ash (FA) from the local Polish power plant "Połaniec" with a varying addition of ground granulated blast furnace slag (GGBFS) from Ekocem (Poland) to prepare geopolymer mortars. The fly ash used has a high silica content (52 wt.\%) and low content of $\mathrm{CaO}$ (wt.\%). The main components of GGBFS are CaO: 44 wt.\% and SiO2: wt.\%. The specific gravity of fly ash (FA) and ground granulated blast furnace slag (GGBFS) was 
$2.1 \mathrm{~g} / \mathrm{cm}^{3}$ and $2.9 \mathrm{~g} / \mathrm{cm}^{3}$, respectively. Siliceous sand $(0 / 2 \mathrm{~mm})$ with the specific gravity 2.65 $\mathrm{g} / \mathrm{cm}^{3}$ was used. The chemical composition of FA and GGBFS are given in Tables 1 and 2 respectively.

Table 1. Chemical analysis of fly ash (FA) in wt.\%.

\begin{tabular}{|l|l|l|l|l|l|l|l|l|l|}
\hline $\mathrm{SiO}_{2}$ & $\mathrm{Al}_{2} \mathrm{O}_{3}$ & $\mathrm{Fe}_{2} \mathrm{O}_{3}$ & $\mathrm{CaO}$ & $\mathrm{MgO}$ & $\mathrm{SO}_{3}$ & $\mathrm{~K}_{2} \mathrm{O}$ & $\mathrm{Na}_{2} \mathrm{O}$ & $\mathbf{P}_{2} \mathrm{O}_{5}$ & $\mathrm{TiO}_{2}$ \\
\hline 52.30 & 28.05 & 6.32 & 3.05 & 1.71 & 0.28 & 2.51 & 0.76 & 0.69 & 1.35 \\
\hline
\end{tabular}

Table 2. Composition of ground granulated blast furnace slag (GGBFS) in wt.\%.

\begin{tabular}{|l|l|l|l|l|l|l|l|l|l|}
\hline $\mathbf{S i O}_{2}$ & $\mathbf{A l}_{2} \mathbf{O}_{3}$ & $\mathbf{F e}_{2} \mathbf{O}_{3}$ & $\mathbf{C a O}$ & $\mathbf{M g O}$ & $\mathbf{S O}_{3}$ & $\mathbf{K}_{2} \mathbf{O}$ & $\mathbf{N a}_{2} \mathbf{O}$ & $\mathbf{C l}^{-}$ & $\mathbf{N a}_{2} \mathbf{O e q}$ \\
\hline 39.31 & 7.61 & 1.49 & 43.90 & 4.15 & 0.51 & 0.356 & 0.468 & 0.038 & 0.702 \\
\hline
\end{tabular}

As an alkaline solution, necessary in the geopolymer synthesis process, an aqueous sodium silicate solution with a molar ratio equal to 1.7 was used. The geopolymer mortars are characterized by sand to binder ratio equal to 1.5, alkaline solution to binder (FA+GGBFS) ratio equal to 0.45 and water to binder (FA + GGBFS) ratio (w/b) equal to 0.30 . All ratio values were constant for all mixtures. The detail mix compositions of all the mortars are presented in Table 3. The mortars were marked with the letter M, followed by the percentage of GGBFS content in the mixture $(0 \%, 10 \%, 30 \%$ and $50 \%)$. The compositions are presented for $1 \mathrm{~m}^{3}$ of mortar.

Table 3. Mix compositions of geopolymer mortars M0, M10, M30 and M50 for $1 \mathrm{~m}^{3}$ of mortar.

\begin{tabular}{|l|c|c|c|c|}
\hline \multirow{2}{*}{ Components } & M0 & M10 & M30 & M50 \\
\cline { 2 - 5 } & {$\left[\mathrm{kg} / \mathrm{m}^{3}\right]$} & {$\left[\mathrm{kg} / \mathrm{m}^{3}\right]$} & {$\left[\mathrm{kg} / \mathrm{m}^{3}\right]$} & {$\left[\mathrm{kg} / \mathrm{m}^{3}\right]$} \\
\hline Alkaline solution & 330,7 & 333.9 & 340.6 & 347.5 \\
\hline FA & 734,9 & 667.9 & 529.8 & 386.1 \\
\hline GGBFS & 0,0 & 74.2 & 227.1 & 386.1 \\
\hline Sand $(0 / 2 \mathrm{~mm})$ & 1102,42 & 1113.2 & 1135.3 & 1158.3 \\
\hline
\end{tabular}

The samples were cast in plastic moulds: prismatic 40x40x160 mm and cylindrical with a diameter of $100 \mathrm{~mm}$ and a length of $200 \mathrm{~mm}$. Just after being casted, samples were compacted on a shaking table and protected from water evaporation. The samples were cured at ambient temperature $\left(18^{\circ} \mathrm{C} \pm 2^{\circ} \mathrm{C}\right)$ and after one day, removed from the moulds and stored in laboratory conditions $\left(\mathrm{T}=18^{\circ} \mathrm{C} \pm 2^{\circ} \mathrm{C}, \mathrm{HR}=75 \%\right)$.

\subsection{Mechanical testing}

The compressive, flexural and splitting tensile strength tests were performed to characterise mechanical properties of the mortars. Flexural tensile strength was determined in three-point bending test with constant load rate of $50 \mathrm{~N} / \mathrm{s}$ on the $40 \times 40 \times 160 \mathrm{~mm}$ specimens. Compressive strength test was performed on the remaining mortar prisms after the flexural bending test. The procedure was adopted according to the standard procedure for cement mortar with a constant load rate of $2400 \mathrm{~N} / \mathrm{s}$. Splitting tensile strength test was performed on discs of 100 $\mathrm{mm}$ diameter and $50 \mathrm{~mm}$ thick, cut from cylinders. This test was also used to characterise tensile pre-and post-peak behaviour of mortars. For this purpose, two CMOD sensors (crackmouth opening displacement) have been attached to a disc specimen at each flat face and their mean value used as a feedback signal during the test in order to reach the post-peak behaviour. The sensors were placed at mid-height of a flat face of a cylindrical specimen and across the potential failure plane (see Figure 1). The two points were distanced by $10 \mathrm{~mm}$, 
sufficiently close to integrate only the area around the crack and sufficiently elongated to let the crack, not exactly rectilinear, pass through. A $250 \mathrm{kN}$ MTS loading cell was employed within a hydraulic loading frame CFM / MTS $1000 \mathrm{kN}$ to perform the tests at the mortars aged approximately 100 days.

a)

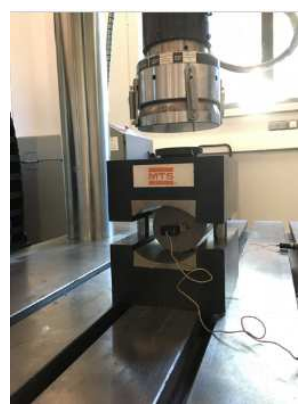

b)

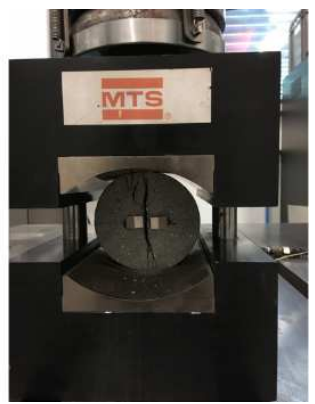

c)

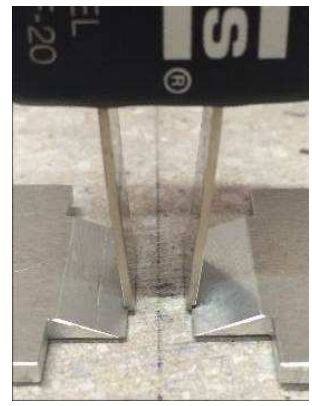

Fig. 1. a) General view of the device b) view of a cracked specimen c) detailed view of the CMOD sensor fitting to a specimen.

\subsection{Permeability measurements}

The device used to test gas permeability is detailed in Figure 2. It includes a permeability cell based on the Cembureau one [21, 22]. The tests are performed using an inert gas (dry nitrogen, N2). A tested specimen, held in place by a fitted collar, is then confined during the tests $(0.8 \mathrm{MPa})$. The gas is injected at the lower surface of the specimen at pressure Pi, equal in this study to $0.1 \mathrm{MPa}$ (relative value) while its upper side remains at atmospheric pressure (Patm). The injection pressure is maintained until the gas flow stabilizes. The pressure and the flow rates are recorded during the test. Flow rates are measured upstream and downstream of the measurement system using thermal mass flowmeters with different capacities used to convert the mass flow rate into an equivalent volumetric gas flow rate in normalized conditions $\left(\mathrm{P}_{0}, \mathrm{~T}_{0}\right)$.

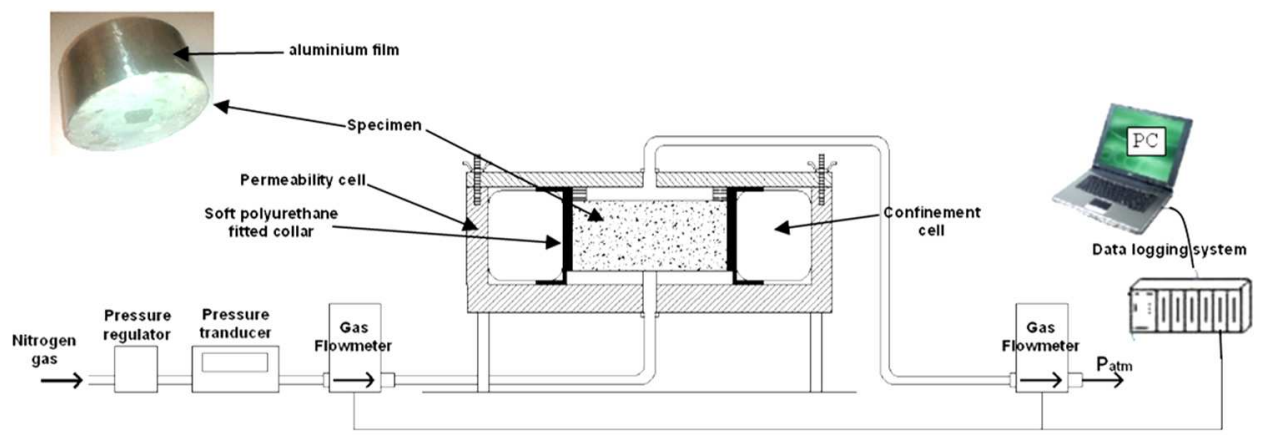

Fig. 2. a) Schematic layout of the permeability device.

Using Darcy's law and mass balance equation, the apparent permeability ka $\left(\mathrm{m}^{2}\right)$ can be determined. Using the thermal mass flowmeters, the resulting solution takes the form [23]:

$$
k_{a}\left(T_{a}\right)=\frac{2 Q_{i}\left(T_{0}, P_{0}\right) P_{0} \frac{T_{a}}{T_{0}} \mu\left(T_{a}\right) L}{S\left(P_{i}^{2}-P_{a t m}^{2}\right)}
$$


where Pi: injection pressure, Ta: room temperature, $\mathrm{P}_{0}=1,013.105 \mathrm{~Pa}, \mathrm{~T}_{0}=273 \mathrm{~K}$, Qi $\left(\mathrm{T}_{0}\right.$, $\left.\mathrm{P}_{0}\right)$ : equivalent volumetric gas flow rate in normalized conditions $\left(\mathrm{m}^{3} / \mathrm{s}\right), \mu$ : nitrogen dynamic viscosity (Pa.s), L: specimen height (m), S: specimen surface $\left(\mathrm{m}^{2}\right)$.

\section{Results and discussion}

Flexural tensile and compressive strength measurements were carried at 1, 3, 7, 14, 28 and 105 days of mortar age. Figure 3 shows the development of strength over time. In the case of flexural strength for the first 28 days, the effect of GGBFS content in the mortar composition is clearly visible; the highest values are noted for M50 and M30 specimens. For samples with lower GGBFS content, respectively lower strength values were observed. After a longer period of time, it can be seen that all mortars with addition of GGBFS obtained similar flexural tensile strength values: approximately $7 \mathrm{MPa}$ after 105 days for M10 and M50 mortars and approximately 8MPa for M30. For mortar without GGBFS, flexural strength was about $6 \mathrm{MPa}$. Anyway, an increase in strength was observed over time for all mortars.

Compressive strength evolution over time followed the same tendencies and the highest compressive strength values was observed for M50 materials at 28 days. After 105 days, M50 specimens obtained an average compressive strength of $104 \mathrm{MPa}$ whereas it was about 40 MPa for M0 specimens.
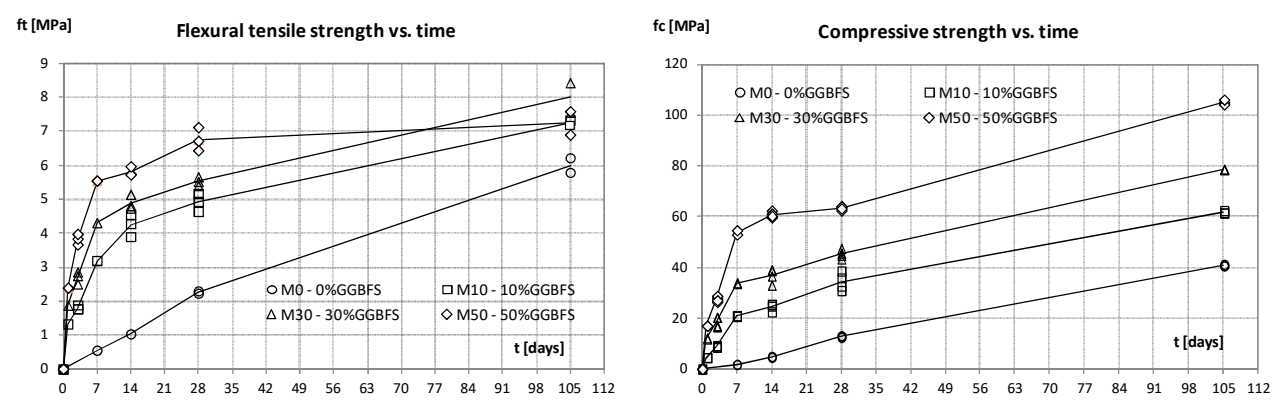

Fig. 3. Flexural tensile and compressive strengths development over time.

Figure 4 compares in detail the flexural tensile and the splitting tensile strength values for mortars after 105 days of aging. Generally, with increasing GGBFS content in the material, an improvement in tensile strength is observed for the both tests, however, a slight decrease is noticed for M50 in comparison to M30 mortars. By the way, the values obtained in the splitting tensile test are lower than those noticed for the flexural tensile strength.
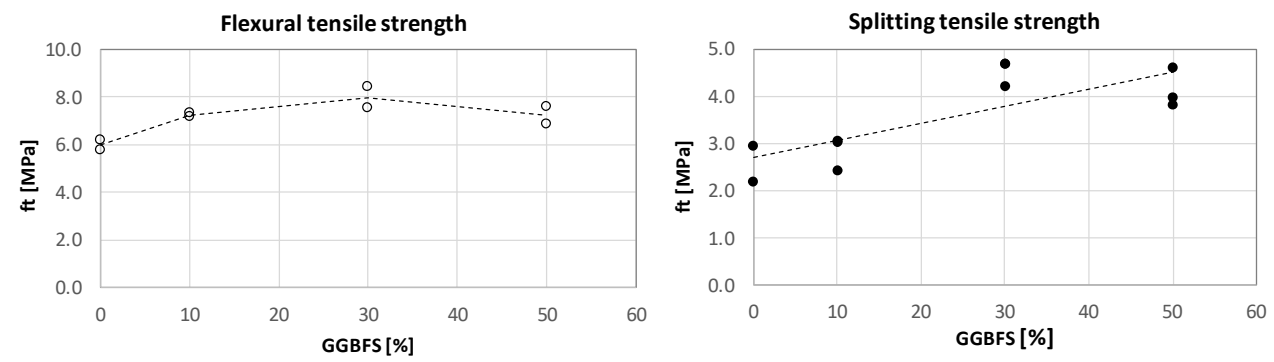

Fig. 4. Flexural tensile and splitting tensile strengths at 105 days of mortars age versus GGBFS content. 
Figure 5 presents the stress-strain behavior of all tested mortar specimens in splitting test performed in the pre- and post-peak phases, carried out up to the mean CMOD value of 50 microns. Each curve follows the same evolution, however, the results follow two master behaviors: one for M0 and M10 mortars and the second one for the M30 and M50 mortars. Those are characterised by higher modulus of elasticity, higher peak values (strength) and higher post-peak plateau, but lower irreversible strains ( Figure 6, where the mean CMOD values are presented instead of strains), in comparison to the M0 and M10 mortars.

The irreversible displacements shown in Figure 6 follow a decreasing linear function versus GGBFS content. Slag addition probably contributes to stiffen the material and therefore to reduce irreversible damage.

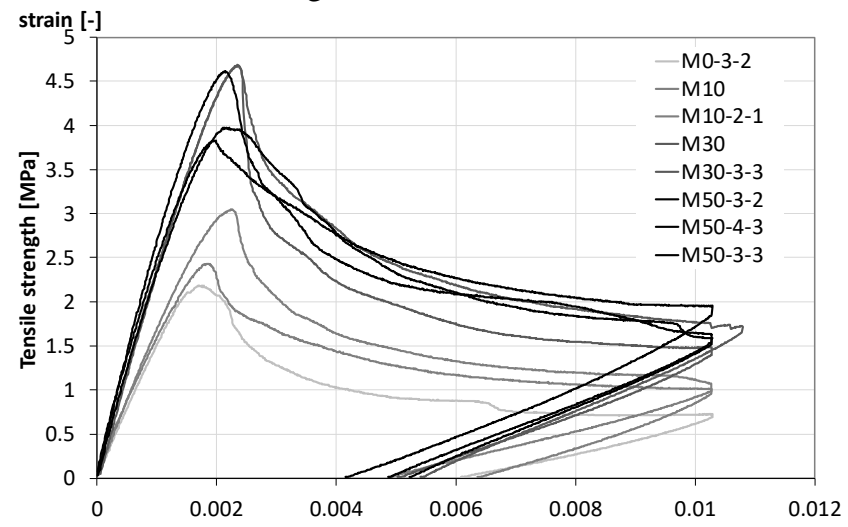

Fig. 5. Stress-strain evolution for mortars in splitting tensile test.

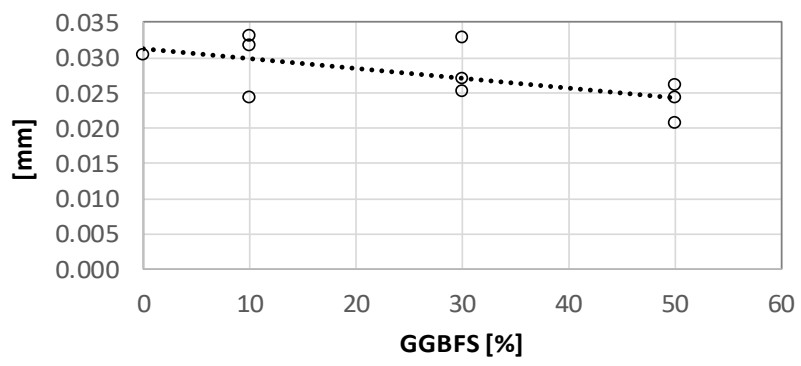

Fig. 6. Irreversible strains versus GGBFS content.

Apparent gas permeability measurements have been performed initially on sound mortar specimens, and then on the same but microcracked specimens, obtained after the final loading and unloading step in the post-peak phase ( Figure 5).

The average value of the initial (before cracking) permeability for M50 mortars was $3.31 .10-17 \mathrm{~m}^{2}$ and $6.09 .10-17 \mathrm{~m}^{2}$ after cracking. For comparison, mortars without the addition of GGBFS (M0) obtained permeability equal to $1.40 .10-16 \mathrm{~m}^{2}$ and to $1.92 .10-16 \mathrm{~m}^{2}$ respectively before and after cracking. The values for M10 are comprised between those for M50 and M0, for M30 the initial values are approximately equal to M50. One may observe (see Figure 7) a positive effect of blending with slag on the apparent gas permeability. However, permeability recovery after cracking appears to be the lowest when blending is the highest (cf Figure 7: the slope decreases for the dotted line, representing the behaviour after cracking, in comparison to the continuous line for the initial permeabilities). The optimal values are therefore obtained for the M30 mortar. 


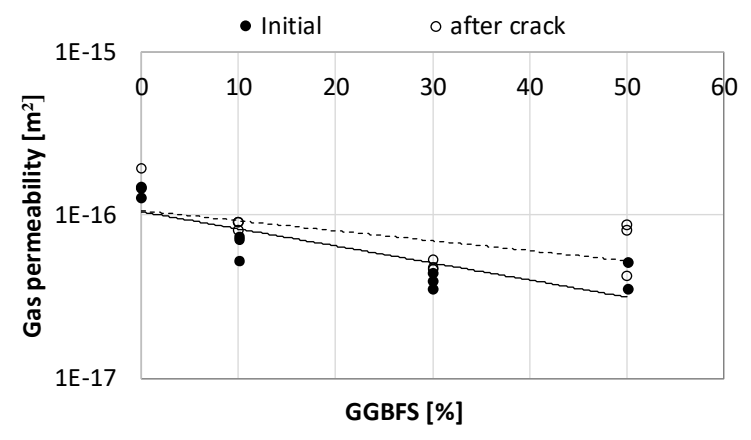

Fig. 7. Apparent gas permeability versus GGBFS content.

\section{Conclusions}

This study demonstrates how the addition of GGBFS to FA-based geopolymer affects the mechanical behaviour and permeability of geopolymer mortars. The results reported in this study show that blending GGBFS with FA makes possible to manufacture sustainable material that is able to set at ambient temperature with no additional temperature curing with satisfying performances. Based on the results, the following observations can be made:

- the addition of a higher GGBFS amount results in an increase in both tensile and compressive strengths;

- the mechanical properties, like stiffness and irreversible strains, are positively affected by blending with GGBFS;

- apparent gas permeability values are of the same order like for cement mortars and generally decreases with GGBFS content;

- however, the optimized behaviour is rather inherent to the M30 mortar (70\% FA, 30\% GGBFS), demonstrating an important permeability recovery after cracking : the permeability value for this material seems to be almost insensitive to cracking effects. Further studies, actually in progress, are needed to develop this issue.

The authors also acknowledge the financial support of the Polish National Agency for Academic Exchange under the International Academic Partnership Programme: PPI/APM/2018/1/00027 Emobility and sustainable materials and technologies EMMAT.

\section{References}

1. L. K. Turner, F. G. Collins, Constr. Build. Mater. 43, 125-130 (2013)

2. T. Bai, Z. Song, H. Wang, Y. Wu, W. Huang, J. Clean. Prod. 226, 114-121 (2019)

3. S. Saha, C. Rajasekaran, Constr. Build. Mater. 146, 615-620 (2017)

4. M. Albitar, M. S. Mohamed Ali, P. Visintin, M. Drechsler, Constr. Build. Mater. 136, 374-385 (2017)

5. P. Duxson, J. Am. Ceram. Soc. 91, 3864-3869 (2008)

6. A. Naghizadeh, S. O. Ekolu, Constr. Build. Mater. 202, 704-717 (2019)

7. M. Sitarz, I. Hager, J. Kochanek, In Proceedings of the MATBUD'2018 - 8th ScientificTechnical Conference on Material Problems in Civil Engineering (Cracow, Poland 2018) 
8. F. Fan, Z. Liu, G. Xu, H. Peng, C. S. Cai, Constr. Build. Mater. 160, 66-81 (2018)

9. T. Bakharev, Cem. Concr. Res. 35, 1224-1232 (2005)

10. T. Bakharev, Cem. Concr. Res. 36, 1134-1147 (2006)

11. D. W. Law, A. A. Adam, T. K. Molyneaux, I. Patnaikuni, and A. Wardhono, Mater. Struct. Constr. 48, 721-731 (2015)

12. T. Bakharev, Cem. Concr. Res. 35(4), 658-670 (2005)

13. T. Bakharev, 35(6), 1224-1232 (2005)

14. P. Zhang, Y. Zheng, K. Wang, and J. Zhang, Compos. Part B Eng. 152, 79-95 (2018)

15. P. Steins et al., J. Appl. Crystallogr. 47(1), 316-324 (2014)

16. D. Medpelli, J. M. Seo, and D. K. Seo, J. Am. Ceram. Soc. 97(1), 70-73 (2014)

17. C. Boher, I. Martin, S. Lorente, and F. Frizon, Microporous Mesoporous Mater. 184, 28-36 (2014)

18. V. Benavent, F. Frizon, and A. Poulesquen, J. Appl. Crystallogr. 49, 2116-2128 (2016)

19. Q. H. Nguyen, S. Lorente, A. Duhart-Barone, and H. Lamotte, Constr. Build. Mater. 191, 853-865 (2018)

20. Y. Hu, Z. Tang, W. Li, Y. Li, and V. W. Y. Tam, Constr. Build. Mater. 226, 139-151, (2019)

21. J. J. Kollek, Mater. Struct. 22, 225-230 (1989)

22. XP P 18-463, Concrete - Testing gas permeability on hardened concrete, French standards, AFNOR (2011)

23. Z.A. Kameche, F. Ghomari, M. Choinska, A. Khelidj, Constr. Build. Mater. 65, 551-565 (2014) 